\title{
Impact of Dancing on Obesity Indices on Bengalee Female Adolescents of Kolkata
}

\author{
Surjani Chatterjee ${ }^{1}$, Neepa Banerjee ${ }^{1}$, Tanaya Santra ${ }^{1}$, Ayan Chatterjee ${ }^{1}$, Sandipan Chatterjee ${ }^{1}$, Indranil Manna ${ }^{3}$, \\ Ushri Banerjee $^{2}$, Shankarashis Mukherjee ${ }^{1, *}$ \\ ${ }^{1}$ Human Performance Analytics and Facilitation Unit, Department of Physiology, \\ ${ }^{2}$ Department of Applied Psychology, University Colleges of Science and Technology, University of Calcutta, 92, APC Road, Kolkata, \\ W.B., India \\ ${ }^{3}$ Department of Physiology, Midnapore College, Midnapore, W. B., India \\ *Corresponding author: msasish@yahoo.co.in
}

Received June 15, 2014; Revised July 25, 2014; Accepted September 18, 2014

\begin{abstract}
Growth spurts generally occurs at adolescents when favourable conditions operate throughout the entire period of growth. This growth, especially in terms of body height, is a mark of a country's socio- economic improvement as well as a child's general condition or health. But along with this growth, the change in the lifestyle is resulting in excess body weight or obesity a serious public health challenge of the $21^{\text {st }}$ century. On the other hand, movement, a basic form of communication, through dance, helps in recreation and to express. In this backdrop, a study has been undertaken to observe the influence of dancing on growth in terms of body height and obesity indices like WHR, WHtR, BAI, BMAI, HAI, CI and CFR in Bengalee female adolescents of Kolkata. 33 adolescent female individuals, receiving dance training for a minimum period of 5 years and practicing regularly for at least an hour for 6 days in a week constituted the dancing group (DG). The control group (CG) had 37 female individuals of comparable age and socio-economic background, but not receiving training in any form of dance or exercise. It was found that the adolescent female individuals practicing dance regularly have significantly $(\mathrm{P}<0.05)$ higher growth but significantly $(\mathrm{P}<0.05)$ lower obesity indices compared to their age matched counterparts. It may be concluded that dance is a cost effective beneficial way of exercising; it can serve as potential tool for growth and optimum body composition in Bengalee female adolescents of Kolkata.
\end{abstract}

Keywords: classical dancing, central obesity, growth, Bengalee, anthropometry

Cite This Article: Surjani Chatterjee, Neepa Banerjee, Tanaya Santra, Ayan Chatterjee, Sandipan Chatterjee, Indranil Manna, Ushri Banerjee, and Shankarashis Mukherjee, "Impact of Dancing on Obesity Indices on Bengalee Female Adolescents of Kolkata." American Journal of Sports Science and Medicine, vol. 2, no. 5A (2014): 40-44. doi: 10.12691/ajssm-2-5A-9.

\section{Introduction}

Somatic growth is a dynamic process influenced by various genetic and environmental factors [1]. Adolescence is the dynamic period of this rapid growth or increase in body size [2]. In industrialized countries, the increase in body height is a mark of socio- economic improvement [3] and is also a statement of a child's general condition or health [1]. In today's context, obesity, extraordinary high amount of fat tissue [4], comes hand in hand with growth. Obesity is a product of an indulgent, comfortable lifestyle [5] and since $21^{\text {st }}$ century the worldwide prevalence of obesity has reached an epidemic dimension which still continues to escalate [6,7]. Metropolitan Life Insurance Company [8] first laid a large scale effort to assess the risk of overweight by developing a table for ideal or desirable weight [9]. Subsequent studies suggested that an obese woman demonstrate a 3.8 fold increased health risk of dyslipidaemia, compared to their healthy weight counterparts [10], and it is also associated with hypertension, other patho-physiological diseases like diabetes and ischemic heart diseases. Recently the different pattern of fat accumulation in male and females (apple or android shape and pear or gynoid shaped respectively) has led to the idea of considering Waist Circumference (WC) and Hip Circumference (HC) as obesity indices. [11,12,13,14]. The Asian population exhibit increased WHR, a central obesity marker, and likely to reflect increased visceral adipose tissue and increased risk $[14,15]$. On the other hand, movement, a basic form of communication, when comes in the form of dance it facilitates the acquisition of sensory, motor, cognitive, social and emotional skills [15]. It also helps to express, while the body acts as a communication vehicle to express feelings and communicate with the environment. Dance, in addition to promoting health and fitness also helps to handle different situations by motor planning, problem solving or social interactions. Evidences indicate that moderate exercise is an important positive health habit; it helps in growth, maturation and provides cardiovascular benefits [2]. There is attempt to trace a link between arts-based learning and human 
development. National Endowment for the Arts established an interagency task force on the arts and human development in the fall of 2011 [16], ensuring that such research continues to inform and strengthen arts educational practice. In this backdrop, a study has been undertaken to observe the influence of dancing on linear growth and WHR on Bengalee adolescent females living in and around Kolkata.

\section{Methodology}

At first, the institutions imparting training on dancing were approached for obtaining permission for carrying out the study on the individuals receiving training on dancing. On obtaining initial consent, the names of volunteers were enlisted and the procedural requirement was explained elaborately. The inclusion criteria were that female adolescent individuals should receive training for a minimum period of 5 years in dance and practice it regularly for at least an hour for 6 days a week. The individuals satisfying the mentioned criteria volunteering for the study constituted the Dancing Group (DG) $(n=33)$. Females of comparable age and socio-economic background, but not receiving training in any form of dance and also not exercising formally constituted the Control Group (CG) ( $\mathrm{n}=37)$. Individuals under medication were excluded. Information about their age (year), daily activities, food habits were recorded in predesigned schedule. Socio-economic status (SES) was measured using the updated Kuppuswamy scale [17]. Body height $(\mathrm{cm})$ using anthropometric rod with an accuracy of $0.1 \mathrm{~cm}$, body weight $(\mathrm{kg})$ using electronic scale with an accuracy of $0.1 \mathrm{~kg}$ with individuals in light clothing and without shoes, were measured and BMI was calculated. Waist Circumference (WC) at the midpoint between the last rib and the iliac crest, with the subject standing, after complete exhalation [18] and Hip Circumference (HC) at the maximum circumference over the buttocks with the arms relaxed at the sides [19] were measured, with an accuracy of $0.1 \mathrm{~cm}$, using a narrow (19 $\mathrm{mm}$ ), flexible, inelastic standard measuring tape and waist hip ratio (WHR) was also calculated. Hip Adiposity Index (HAI), Body Adiposity Index (BAI) [20], Conicity Index (CI) [21], Waist to Body Height Ratio (WHtR) and Body Mass Abdominal Index (BMAI) were calculated. Centripetal Fat Ratio was found out with skinfold measurement nearest to $0.1 \mathrm{~mm}$ at two sites: tricep [22] (measured on the right upper arm, midway between the acromion and the olecranon) and subscapula (measured two fingers below the low point of the right scapula) [23] using skinfold calliper. To diminish the inter-measurement variation coefficients, all anthropometrical measurements were performed by the same researcher. The data of DG and CG were compared to find out any significant difference. $\mathrm{P}$ value lower than $0.05(\mathrm{P}<0.05)$ was considered significant.

\section{Results}

There were 33 individuals in DG, of age $15.2 \pm 1.02$ year; and 37 volunteers constituted the CG; their age being $15.6 \pm 1.23$. The DG and CG individuals were not differing significantly in respect of their age. In Figure 1, the body height in $\mathrm{cm}$ (a) and the body weight in $\mathrm{kg}$ (b) data have been presented.

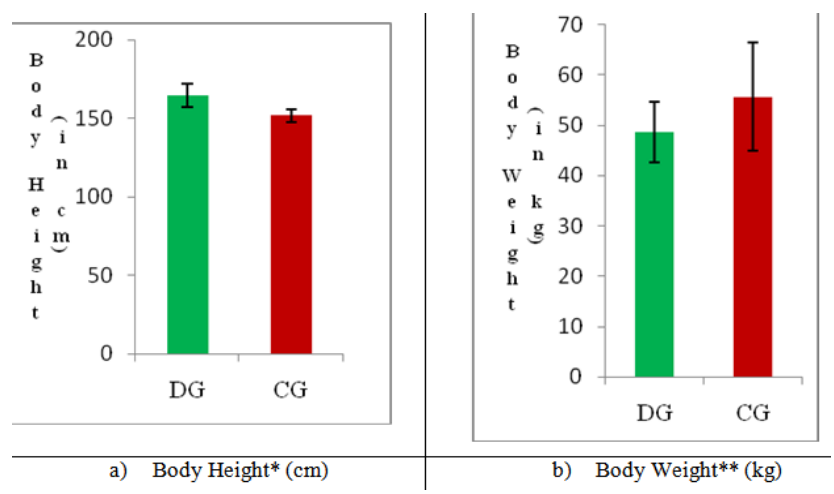

Figure 1. Comparison between DG and CG individuals in respect of $\mathrm{BH}$ and $\mathrm{BW}(* \mathrm{P}<0.05, * * \mathrm{P}<0.01)$

In Figure 2, the Obesity indices in terms of Body Adiposity Index, BAI and Body Mass Abdominal Index, BMAI have been presented. In terms of BMAI, the DG and CG individuals differ significantly $(\mathrm{P}<0.01)$, with CG individuals having adverse values.

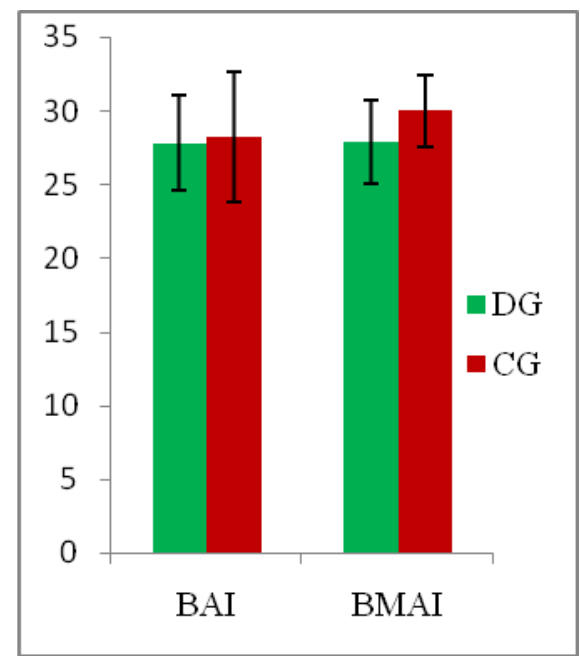

Figure 2. Comparison between DG and CG individuals in respect of BAI and BMAI

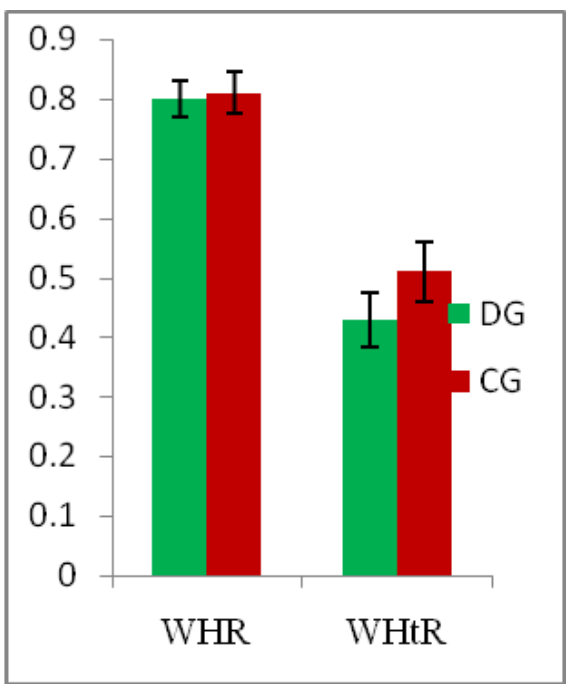

Figure 3. Comparison between DG and CG individuals in respect of WHR and WHtR 
In Figure 3, the obesity indices in terms of Waist to Hip Ratio, WHR and Waist to Body Height Ratio, WHtR have been presented. In terms of WHtR, the DG individuals are in significantly $(\mathrm{P}<0.01)$ favorable state, compared to their CG counterparts having adverse values. In Figure 4, the obesity indices in terms of Hip Adiposity Index, HAI (a) Conicity Index, CI (b) and Centripetal Fat Ratio, CFR (c) have been presented.

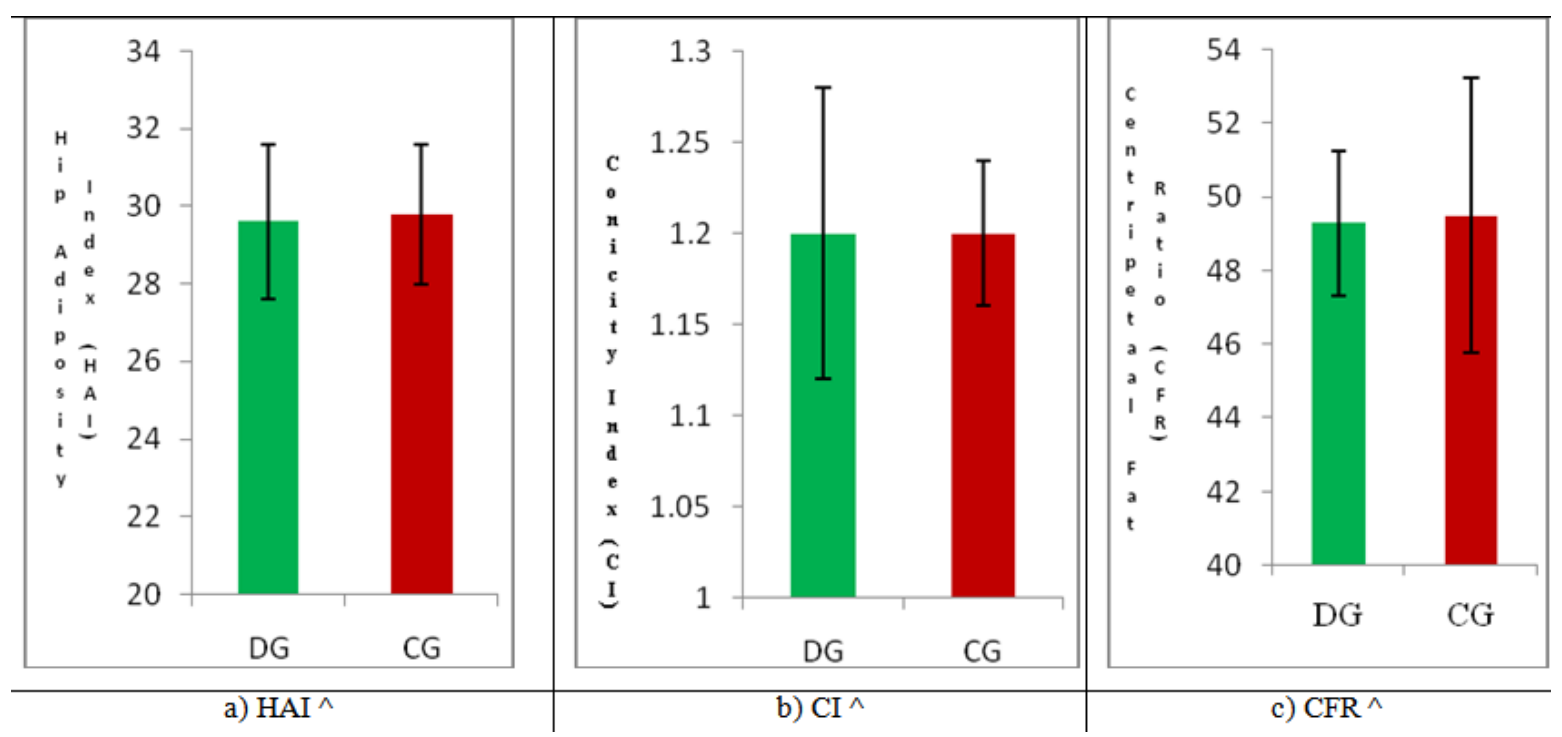

Figure 4. Comparison between DG and CG individuals in respect of HAI, CI and CFR $(\wedge$ ns)

\section{Discussions}

The mean body height of the DG individuals was 164.6 $\mathrm{cm}$, which is significantly higher $(\mathrm{P}<0.05)$ than that of CG individuals with body height $151.6 \mathrm{~cm}$ (Figure $1 \mathrm{a}$ ). As per WHO guideline on body height for age for girls, the height for 14year and 15 year old girls should be about $156 \mathrm{~cm}$ and $160 \mathrm{~cm}$ respectively [24]. The body height of the DG satisfies the recommended value, whereas that of CG does not, indicating a better growth in terms of body height in the DG individuals. The mean body weight of the DG individuals is significantly lower $(\mathrm{P}<0.01)$ than their age matched CG counterparts (Figure $1 \mathrm{~b}$ ). As the body height of the CG individuals is lower than the DG individuals, a higher body weight indicates a higher BMI, the ratio of subject's body weight (in $\mathrm{kg}$ ) to the squared stature (m), that is now considered one of the most commonly used indicator of obesity [25]. Adolescents are defined as obese when BMI equals to or exceeds the agegender-specific $95^{\text {th }}$ percentile. Those with BMI equal to or exceeding the $85^{\text {th }}$ but are below $95^{\text {th }}$ percentiles are defined overweight and are at risk for obesity related comorbidities [26]. The trend of result of the present study is in agreement with the findings of Wyon [27].

Recent other studies show the trend of abdominal obesity to be increasing, in both developed and developing countries [28]. There is a significant positive trend of increased central adiposity and fat distribution in sedentary adolescents in the urban population and hence the estimation of the central adiposity indicators is important. Body Adiposity Index (BAI), predictor of body fat [29], is an alternative index based on hip circumference and body height [30]. BAI, a method of estimating body adiposity without assessment of body weight [31], offers a simple-to-use tool, is more accurate indicator than that achieved by other measures of body size. In the present study, the CG individuals have been found to have a higher value of BAI (Figure 2); this can be attributed to their larger hip circumferences [20], which is an indicator of higher plasma CRP, indicating insulin resistance and metabolic disorder, in obese females [32]. The mean Body Mass Abdominal Index (BMAI) of the DG individuals (27.9) is significantly lower $(P<0.01)$ than their $C G$ counterparts (30.0) which reduce the likelihood of having health related co -morbidities in the DG individuals. Waist Hip Ratio (WHR) is an important indicator for defining central obesity and cardiovascular risk. The Asian population exhibit increased WHR and is likely to reflect increased visceral adipose tissue and increased risk [16]. Visceral adiposity induces greater endocrine activity by modulating tissue concentrations of adipokines such as adiponectine and resistine , markers of insulin resistance, or by transforming growth factor $\alpha$ and interleukin 6 , inflammatory mediators 2 (C). It is also found that the risk of myocardial infarction was more strongly associated with WHR than with WC. In the present study the DG individuals have lower value of WHR, though not significantly different, and are in agreement with the works of [27] (Figure 3). The cut- off limit for WHR is 0.80 which is slightly exceeded by the CG individuals indicating a probability of onset of obesity. It has also been reported that Waist-to-Height Ratio (WHtR) is a better predictor of abdominal obesity, and is more closely related to CVD morbidity and mortality. The mean WHtR of the DG individuals is significantly lower $(P<0.01)$ than the CG individuals preventing the DG individuals from the adult onset of obesity.

Hip Adiposity Index (HAI), which is generally explained in terms of Polygenic Epistasis, is found to be lower, though not significantly, in DG individuals, compared to the CG individuals (Figure 4). In Figure 4 the conicity index (CI), another measure of central adiposity is presented. It is based on quantifying the deviation from the circumference of an imaginary cylindrical shape model, with the help of body height, body weight and WC of the individuals, has good association with WHR; its rise indicates higher degree of abdominal obesity. The 
relation of body fat mass and circulating CRP levels, a marker of systemic inflammation, has been confirmed in other studies. Thus CI, that detects changes in body composition, permits comparison between subjects with different body weight and body height measurements [33]. $\mathrm{CI}$ is also found to be related with atherogenic risk factors to an extent similar to that of WHR in adults, but has the advantage of calculating central adiposity without the measurement of hip circumference. CI is correlated to systolic blood pressure. Thus CI is considered to be a better indicator, compared with WHR for identifying adolescents with high trunk fat.

Among other methods, anthropometric measurements play an important role in Body Fat estimation especially in clinical practice. Ratios of two skinfolds, ticeps and subscapula [34], are used to calculate Centripetal Fat Ratio (CFR); it is widely used to rank individuals in terms of central adiposity. Fat patterning, associated with Cardiovascular risk, have been the focus of research for the past three. Further studies have found fat distribution to be a risk factor for diabetes and coronary artery disease. The mean CFR of CG individuals is slightly higher than DG individuals (Figure 4), indicating a higher subscapular skinfold which is a trunk fat pattern site for the females [35].

The results of the present study show an increasing trend of obesity and abdominal obesity in the sedentary urban adolescent population of Kolkata.Earlier studies have found that dancing exercise plays an important role in the prevention of becoming overweight, reducing the risk of obesity in adulthood [36,37] and attaining favorable impact on body composition [27] which is further confirmed in the present study for the Bengalee adolescent females of Kolkata.

\section{Conclusion}

On the basis of the study, it could be concluded that dancing, if practiced regularly for at least an hour for 6 days in a week, has beneficial impact on maintaining growth assessed in terms of body height and on attaining favorable body composition variables, adjudged anthropometrically in adolescents; the favorable body composition thus attained could reduce the chance of onset of obesity in adulthood and related diseases.

\section{Acknowledgement}

The authors are thankful to all the volunteers participating in the study for their cooperation and the concerned institutional authorities for their kind consent.

\section{References}

[1] Rogol AD, Clark PA, Roemmich JN, Growth and pubertal development in children and adolescents: effects of diet and physical activity, Am J Clin Nutr, 72, 521-528, 2000.

[2] Georgopoulos NB, Markou KB, Theodoropoulou A, Vagenakis GA, Mylonas P, Vagenakis AG, Growth, pubertal development, skeletal maturation and bone mass acquisition in athletes, HORMONES, 3 (4), 233-243, 2004.

[3] Tanner JM, Fetus into Man: Physical Growth from Conception to Maturity, Cambridge, MA: Harvard University Press, 1989.
[4] Kirchangast S, Human Obesity from Viewpoint of Evolutionary Medicine, Health Consequences of Human Central Obesity, 57-70, 2014.

[5] Armstrong DB, Dublin LI, Wheatley GM, Mark HH, Obesity and its Relation to Health and Diseases, J. Am. Med. Assoc, 147 (11), 1007-1014, 1951.

[6] Deitel M, Overweight and Obesity Worldwide Now Estimated to Involve 1.8 billion people, Obes. Surg, 13, 329-330, 2013.

[7] Hossain P, Kawar B, Nahas M, Obesity and Diabetes in the Developing World-A Growing Challenge, New Eng. J. Med, 356, 213-215, 2007.

[8] Metropolitan Life Insurance Company (MLIC) 1983, Metropolitan Height and Weight Tables, Stat. Bull, 64, 2-9, 1983.

[9] Valdez R, Kim S, An Approach to Examine the Contribution of Waist Circumference to the Health Risks Attributes to Obesity in Adults, Health Consequences of Human Central Obesity, 1-11, 2014.

[10] Brown CD, Higgins M, Donatok A, Rohde FC, Garrison R, Oberzanek E, Ernst ND, Horan M, Body Mass Index and the Prevalence of Hypertention and Dyslipidemia, Obesity, 8 (9), 605619, 2000.

[11] Limieux S, Prud' home D, BouchardC, Tremblav A, Despres JP, A Single Threshold Value of Waist Girth Identifies Normal Weight and Overweight Subjects with Visceral Adipose Tissue, Am J Clin Nutr, 64, 685-693, 1996.

[12] Zimmet D, Albert KGM, Kaufman F, Tajma N, Silink M, Arslanian S, Wong G, Bennett P, Shaw J, Caprio S, Group 1c, The Metabolic Syndrome in Children and Adolescents-An IDF Census Report, Pediatr. Diabetes, 8, 299-306, 2007.

[13] Elliot S, Nancy LK, Judith SS, Karen T,Peter JH, Fructose, Weight GainandInsulin Resistance Syndrome, Am J Clin Nutr, 76 (5), 911-922, 2002.

[14] Prasad DS, Kabir Z, Dash AK, Das BC, Abdominal Obesity, an Independent Cardiovascular risk Factor in Indian Subcontinent: A Clinioepidemiological Evidence Summary, J. Cardiovasc. Dis. Res, 2, 199-205, 2011.

[15] Deurenberg-Yap M, Yian TB, Kai CS, Deurenberg P, Staveren WA, Manifestation of Cardiovascular Risk Factor at Low Levels of Body Mass Index and Waist to Height Ratio in Singaporian Chinese, Asia Pacific J. Clin Nutr, 8, 177-183, 1999.

[16] Hanna, Controls of meiotic signaling by membrane or nuclear progestin receptor in zebrafish follicle-enclosed oocytes, Molecular and Cellular Endocrinology, 337 (1-2), 80-8, 2011.

[17] Kuppuswamy B, Manual of Socioeconomic Status, Manasayan (1981).

[18] Hu G, Tuomilehto J, Silventoinen K, BarengoN, Jousilahti P, Joint Effects of Physical Activity, Body Mass Index, Waist Circumference and Waist-to-Hip Ratio with the Risk of Cardiovascular Disease among Middle-Aged Finnish Men and Women, European Heart Journal, 25, 2212, 2004

[19] Janssen I, Katzmarzyk PT, Ross R, Waist Circumference and not Body Mass Index Explains Obesity Related Health Risk, Am J Clin Nutr, 79, 379, 2004.

[20] Freedman DS, Thornton J, Sunyer JX, Heymsfield SB, Wang J, Pierson RN, Blanck HM, Gallagher D, The body adiposity index (hip circumference $\div$ height1.5) is not a more accurate measure of adiposity than is BMI, waist circumference, or hip circumference, Obesity, 20, 2438-2444, 2012

[21] Pal A, Chatterjee S, De S, Sengupta P, Dhara PC et al, Relationship Between Obesity and CRF among Office Worker, Human Obesity from Viewpoint of Evolutionary Medicine, Health Consequences of Human Central Obesity, 185-204, 2014.

[22] Twitchett E, Angioi M, Metsios GS, Koutedakis Y, Wyon M, Body composition and ballet injuries: a preliminary study, Medical Problems of Performing Artists, 93, (2008).

[23] Ferrari EP, Silva DAS, Martins CR, Fidelix YL, Petroski EL, Morphological characteristics of professional ballet dancers of the Bolshoi theater company, Coll. Antropol, 37, 37, 2013.

[24] Bremer Z, Dance as an Exercise, The British Journal of General Practice, 57, 166, 2007.

[25] Kostić R, Đurašković R, Miletić D, Mikalački M, Body Composition of Women Under the Influence of the Aerobic Dance, Physical Education and Sport, 4, 59, 2006.

[26] Raj M, Kumar R, Obesity in children \& adolescents, Indian J Med Res, 132, 598-607, November 2010.

[27] Wyon M, Allen N, Angioi M, Nevill A, Twitchett E, Anthropometric Factors Affecting Vertical Jump Height in Ballet 
Dancers, Journal of Dance Medicine \& Science, 10, 106-110, 2006

[28] C I Karageorghis, PC Terry, Today 5, Sports Med, 38-41, 2001.

[29] S Mukherjee, N Banerjee, S Chatterjee, B Chakrabarti, Impact of Bharatnatyam Dancing Exercise in Reducing Central Obesity in Adult Bengalee Females, Sci \& Cult, 79 (11-12), 503-506, 2013.

[30] Ogden CL, Carroll MD, Kit BK, Flegal KM. Prevalence of obesity and trends in body mass index among US children and adolescents, 1999-2010, Journal of the American Medical Association, 307 (5), 483-490, 2012

[31] D. J Kumari1, B. S Krishna, Prevalence and Risk Factors for Adolescents (13-17 Years): Overweight and Obesity, Current Science, 100, February 2011.

[32] Jou H, Hsu IP, Ling PY, Lin CT, Tsai ST, Huang HT, Wu SC, Hip circumference is an important predictor of plasma C-reactive protein levels in overweight and obese Taiwanese women, Taiwan J Obstet Gynecol, 45 (3), 215-20, (2006).
[33] Ruperto M, Barril G, Sánchez-Muniz FJ, Conicity index as a contributor marker of inflammation in haemodialysis patients, Nutr Hosp, 28 (5): 1688-1695, 2013.

[34] Wells JCK,Victora CG, Indices of whole-body and central adiposity for evaluating the metabolic load of obesity, International Journal of Obesity, 29, 483-489, 2005.

[35] Becque DM, Ha'ltori K, Katch Vl, Rocchin AP, Relationship of Fat Patterning to Coronary Artery Disease Risk in Obese Adolescents, American Journal Of Physical Anthropology, 71, 423-429, 1986.

[36] PA Donohoue, RE Behrman, RM Kleigman, HB Jenson, Obesity. In, Nelson Textbook of Pediatrics, 17th ed, 173-7, 2004.

[37] V Andreasi, E Michelin, A.E.M Rinaldi, R C Burini, Physical fitness and Associations with Anthropometric Measurements in 7 to 15-year-Old School Children, Jornal de Pediatria , 86, 2010. 